\title{
Dynamic imaging in suspected Eagle syndrome
}

\author{
Enrico Nastro Siniscalchi ${ }^{1}$ (1)
}

Received: 9 September 2019 / Accepted: 30 September 2019 / Published online: 15 October 2019

(c) Springer-Verlag GmbH Germany, part of Springer Nature 2019

\section{Dear Editor}

I have recently read the article of Ayyildiz et al. on Morphometric examination of the styloid process by 3D-CT in patients with Eagle syndrome.

The article focuses the attention on the importance of a correct imaging diagnosis in order to better clarify styloid relationship with other structures even in the presence of a styloid process of normal length. Lateral and medial deviations can occur, in fact, in a normal styloid process but, at the same time, can cause compression of vessels and nerves. The article, moreover, underlines the importance of a correct diagnosis focusing not only on the length of styloid process (which could be normal), but even on the direct relationship between styloid and the vascular and neural near structures even in the presence of a process of normal length and $\mathrm{C} 1$ Transverse Process. Our recent experience focuses the attention on the "dynamic" relationship between SP and near structures. In particular, above all in the vascular variant, neurological signs seem to be often influenced by the position of head and neck, varying in the same patient from a position to another. As a consequence of this strong influence of head and neck position we think that, in the case of a suspected ES, a standard "static" tool could not be sufficient to better clarify the relationship between styloid and other structures. In other words, in case of suspected ES imaging tool like MRI and ultrasonography of the head and neck region should be taken in different position of the head, being the structures involved in such syndrome conditioned by the different positions of the entire head and neck region. Hence, we usually perform a double tool including MRI and Ultrasonography in the same standardized five positions of the head: rest position, maximum extension, maximum flexion of the head, maximum right and maximum left rotation. We do think that this method, in case of a suspected vascular Eagle syndrome, may help in the differential diagnosis to not misdiagnose ES which could be underestimated in case of a static tool imaging acquisition.

\section{Compliance with ethical standards}

Conflict of interest The authors declare that they have no conflict of interest.

Research involving Human Participants and/or Animals This article does not contain any studies with human participants or animals performed by any of the authors.

Informed consent Informed consent was obtained from all individual participants included in the study.

\section{Reference}

1. Ayyildiz VA, Senel FA, Dursun A, Ozturk K (2019) Morphometric examination of the styloid process by $3 \mathrm{D}-\mathrm{CT}$ in patients with Eagle syndrome. Eur Arch Otorhinolaryngol

2. Galletta K, Siniscalchi EN, Cicciù M, Velo M, Granata F (2019) Eagle syndrome: a wide spectrum of clinical and neuroradiological findings from cervico-facial pain to cerebral ischemia. J Craniofac Surg 30(5):e424-e428

Publisher's Note Springer Nature remains neutral with regard to jurisdictional claims in published maps and institutional affiliations.

This comment refers to the article available online at https://doi. org/10.1007/s00405-019-05602-6.

Enrico Nastro Siniscalchi

enastrosiniscalchi@unime.it

1 Unit of Maxillofacial Surgery, Department of Biomorphology,

University of Messina, Messina, Italy 